\title{
Assessment of 10-year absolute fracture risk: a new paradigm with worldwide application
}

\author{
E. Siris • P. D. Delmas
}

Published online: 23 February 2008

(C) International Osteoporosis Foundation and National Osteoporosis Foundation 2008

In this issue of Osteoporosis International we present several papers representing common approaches to the evaluation of fracture risk [1-5]. This represents a considerable change for the field, moving from descriptions of risk as "relative risk," as occurs on the output of DXA equipment, to what might be called "absolute risk" or "real risk," neither of which is an adequate description. The model allows an assessment of the likelihood of hip or major osteoporosis-related fracture within a specific time frame (10 years) for individual patients.

These analyses result from a "mega-analysis" conducted by a team of investigators on behalf of the World Health Organization, led by Dr John Kanis. In this study Kanis and colleagues took data from epidemiological studies from the USA, Europe, Australia and Asia and determined the factors that were common to all that independently increased the risk of fractures in the aging population. They then modeled overall fracture risk using these factors, making the model generally usable throughout the world. In order to apply the model, each country simply would have to know the epidemiology of osteoporosis-related fractures, their outcomes, and mortality rates, and risk models could be calculated. Where country-specific fracture data are not available, data from other countries with similar ethnic

\footnotetext{
E. Siris $(\bowtie)$

National Osteoporosis Foundation

e-mail: es27@columbia.edu

URL: www.nof.org

P. D. Delmas $(\bowtie)$

International Osteoporosis Foundation

email: delmas@lyon.inserm.fr

URL: www.iofbonehealth.org
}

make-up can be substituted, with the realization that risk calculations made in this way are more prone to error.

Using these risk assessments a health economic strategy can be formulated for each country, based on acceptable levels of resource utilization, to determine at what level of risk it would be cost effective to intervene. To do this requires more information than fracture epidemiology, including costs and the efficacy of the intervention strategies to reduce the risk of the fractures considered in the model, something that has to be derived from clinical trial data, which may or may not address these specific fractures. From these data intervention strategies can be developed, which will vary from country to country.

This methodology brings this field somewhat into line with cardiovascular disease and breast cancer risk reduction, where data from Framingham have been used in this fashion in clinical decision making, as has the Gail model for the latter. Clearly, however, this does not change the concept of osteoporosis defined as a bone mineral density (at the hip) 2.5 SD below the average value for young adults. In at least some countries this will, by itself, convey a risk of sufficient magnitude to require intervention. The model does allow the identification of those in the low BMD range (T-score -1 to -2.5 ) who have the highest risk of fracture and would benefit for treatment. This is an important advance, since overall in this population the risk of fracture is low, but by virtue of numbers, total fractures exceed those occurring in persons with osteoporosis. Two other features of the model are clinically important. It allows for risk stratification in men, and across race. Finally, it aids in identifying persons with co-morbid conditions that increase fracture risk, and allows targeting of the high-risk populations here for intervention. 
The concept and the model development have been supported by the IOF and NOF, and both organizations strongly advocate its use in clinical decision making. The National Osteoporosis Foundation in the USA will be releasing a new Physician's Guide applying the WHO algorithm to postmenopausal women and older men in the US population (www.nof.org) that is based upon the data in the papers in this issue from the NOF Guide Committee. Other support from the UK and Japan is indicated by inclusion of papers reflecting the adaptation of the model to those populations. Data for other countries such as Sweden have already been published, and we hope that others will follow.

Finally, this issue contains European guidelines on the diagnosis and management of osteoporosis from the scientific committee of the European Society for the Clinical and Economic Evaluation of Osteoporosis (ESCEO) that review the most recent evidence on clinical efficacy/safety of treatments and integrate the recent developments described above [6].

\section{References}

1. Kanis JA, Johnell O, Oden A, Johansson H, McCloskey E (2008) FRAX $^{\mathrm{TM}}$ and the assessment of fracture probability in men and women from the UK. Osteoporos Int DOI 10.1007/s00198-007-0543-5

2. Fujiwara S, Nakamura T, Orimo H, Hosoi T, Gorai I, Oden A, Johansson H, Kanis JA (2008) Development and application of a Japanese model of the WHO fracture risk assessment tool (FRAX ${ }^{\mathrm{TM}}$ ). Osteoporos Int DOI 10.1007/s00198-007-0544-4

3. Tosteson ANA, Melton III LJ, Dawson-Hughes B, Baim S, Favus MJ, Khosla S, Lindsay RL (2008) Cost-effective osteoporosis treatment thresholds: the United States perspective. Osteoporos Int DOI 10.1007/s00198-007-0550-6

4. Dawson-Hughes B, Tosteson ANA, Melton III LJ, Baim S, Favus MJ, Khosla S, Lindsay RL (2008) Implications of absolute fracture risk assessment for osteoporosis practice guidelines in the USA. Osteoporos Int DOI 10.1007/s00198-008-0559-5

5. Leslie WD for the Manitoba Bone Density Program (2008) Absolute fracture risk reporting in clinical practice: a physiciancentered survey. Osteoporos Int DOI 10.1007/s00198-008-0565-7

6. Kanis JA, Burlet N, Cooper C, et al. (2008) European guidance for the diagnosis and management of osteoporosis in postmenopausal women. Osteoporos Int DOI 10.1007/s00198-008-0560-z 